\title{
Outcome of Sublingual Immunotherapy in Patients With Allergic Rhinitis Sensitive to House Dust Mites
}

\author{
Seon-Tae Kim*
}

Department of Otolaryngology, Gil Medical Center, School of Medicine, Gachon University, Incheon, Korea

This is an Open Access article distributed under the terms of the Creative Commons Attribution Non-Commercial License (http://creativecommons.org/licenses/by-nc/3.0/) which permits unrestricted non-commercial use, distribution, and reproduction in any medium, provided the original work is properly cited.

Sublingual immunotherapy (SLIT) was recently developed and is widely used in Europe. SLIT has been reported to be well-tolerated and effective for the treatment of allergic rhinitis (AR) and asthma in children, adults, and elderly patients. ${ }^{1,2} \mathrm{Sev}-$ eral systemic reviews indicate that the use of SLIT in patients with AR sensitive to house dust mites (HDMs) yielded significantly lower symptom scores and better clinical outcomes. ${ }^{3-5}$ Recent studies support the use of SLIT as the first-choice treatment for AR and asthma compared to medication and subcutaneous immunotherapy (SCIT). ${ }^{6}$ Nevertheless, conflicting results on the efficacy of SLIT in patients with AR sensitive to HDMs have appeared, and no consensus has yet been formed in terms of the basic treatment parameters (e.g., dose and duration) for HDMs-SLIT.

This study published in this issue is the first investigation to observe the clinical outcomes of long-term SLIT in patients with AR sensitive to HDMs in Korea. ${ }^{8}$ Effective responses after 3 years' treatment in aspects of total symptom scores was $72 \%$, similar to other studies. ${ }^{3,5,9}$ The HDM-SLIT for 2 years in 736 pediatric AR patients sensitive to HDM was found to be effective in $\mathbf{8 3 . 8 \%}$ with decrease in rescue medication scores. ${ }^{9}$ A large retrospective study demonstrated that HDM-SLIT was effective or very effective with reduction in medication scores in $82 \%$ of 1,289 respiratory allergy patients after 2 years' treatment. Most patients were well tolerated and satisfied with their treatment. ${ }^{3}$ Another study randomized 509 adults with HDM-sensitive AR to administer 2 types of HDM sublingual tables, 500-index of reactivity (IR) and 300-IR, for 1 year showed that both tablets significantly reduced the mean symptom scores compared with placebo. The efficacy of both tablets was maintained during the treatment-free follow-up period. ${ }^{5}$ However, the present study in this issue is a single-center study and the number of study subjects was not large enough compared with previous investigations. ${ }^{3,5,9}$ The compliance was lower, which may be related with higher cost than other treatment modalities in Korea. ${ }^{8}$
The present study evaluated the effective response rate of HDM-SLIT from 6 months to 3 years. ${ }^{8}$ No significant differences were noted in the effective response rate between groups, even the effect of 6-month group tended to be higher than other groups. These results may be derived from high drop-out rate of the patients who experienced improvement in their symptoms after 6 months' treatment. The effective response was observed after 6 months' treatment in this study which was comparable with previous studies demonstrating that favorable effect of SLIT was observed from 14 to 24 weeks of treatment. ${ }^{5,10,11}$ SLIT roughly halved the clinical scores at the end of the first year, and the scores remained low over the second and third years of therapy. ${ }^{12}$ The reduction in the symptoms scores was more evident after 2 years of treatment, although improvement was observed from the first year of treatment with SCIT in HDM-sensitive childhood patients. ${ }^{13}$ To analyze the outcomes of the study subjects who had completed 3 years' treatment will enable to further validate the effective response of HDM-SLIT in AR patients in this country. Most studies suggest that the effective response can be persistent longer with longer duration of SLIT. ${ }^{14,15}$ These findings suggest that SLIT is recommend for more than 3 years to maintain the longer period of effective response.

The mean age of the patients in the present study was 19.1 years (range, 5-59 years) including adult and pediatric patients. ${ }^{8}$ SLIT is considered as an alternative to SCIT or pharmacotherapy for children with AR; however, the efficacy of SLIT in children with AR sensitive to HDMs remains controversial. Further analysis will be needed to compare the effective response of

Correspondence to: Seon-Tae Kim, MD, PhD, Department of Otolaryngology, Gil Medical Center, School of Medicine, Gachon University, 21 Namdong-daero 774beon-gil, Namdong-gu, Incheon 405-760, Korea.

Tel: +82-32-460-3764; Fax: +82-32-467-9044; E-mail: rhinokim2002@hanmail.net Received: January 22, 2015; Accepted: January 23, 2015

- There are no financial or other issues that might lead to conflict of interest. 
HDM-SLIT in child and adult groups separately, although the efficacy of HDM-SLIT between pediatric and adult patients after 1 year did not differ significantly between the groups. ${ }^{16}$

Limitations of this study are the lack of a control group. ${ }^{8}$ The present study did not employ a double-blind placebo approach; thus, there was no medication-only or placebo control groups. Some AR patients may improve spontaneously without allergen immunotherapy. Furthermore, the follow-up improvement after stopping SLIT was not observed.

The major outcome parameters of SLIT are the medication and symptom scores. Also, immunologic parameters such as the changes of serum specific IgE and IgG4 antibodies can be measured, which were not done in the present study. ${ }^{8}$ However, these findings are still conflicting: SLIT lasting longer than 3 years in children monosensitized to HDMs was not associated with a significant change in serum specific IgE to HDMs, ${ }^{17}$ while SLIT-treated patients exhibited a significant decrease in serum specific IgE to HDMs with no significant changes in specific IgG1 and IgG4 antibodies. ${ }^{18}$ Further immunologic findings including the changes of $\mathrm{T}$ cells and basophils should be followed over the period of SLIT.

In conclusion, most SLIT studies have shown benefits in AR patients sensitive to HDMs. However, they involved small numbers of patients and used variable doses of HDM allergens. The optimal dose and duration of SLIT remain unclear, because the density and quality of HDM allergens vary according to the manufacturer. Additional investigations are essential in order to recommend HDM-SLIT as a primary treatment modality for AR patients sensitive to HDMs.

\section{REFERENCE}

1. Bozek A, Ignasiak B, Filipowska B, Jarzab J. House dust mite sublingual immunotherapy: a double-blind, placebo-controlled study in elderly patients with allergic rhinitis. Clin Exp Allergy 2013;43:242-8.

2. Nuhoglu Y, Ozumut SS, Ozdemir C, Ozdemir M, Nuhoglu C, Erguven $\mathrm{M}$. Sublingual immunotherapy to house dust mite in pediatric patients with allergic rhinitis and asthma: a retrospective analysis of clinical course over a 3-year follow-up period. J Investig Allergol Clin Immunol 2007;17:375-8.

3. Trebuchon F, David M, Demoly P. Medical management and sublingual immunotherapy practices in patients with house dust miteinduced respiratory allergy: a retrospective, observational study. Int J Immunopathol Pharmacol 2012;25:193-206.

4. Cingi C, Bayar Muluk N, Ulusoy S, Acar M, Sirin S, Cobanoğlu B, et al. Efficacy of sublingual immunotherapy for house dust mite allergic rhinitis. Eur Arch Otorhinolaryngol. Forthcoming 2014.

5. Bergmann KC, Demoly P, Worm M, Fokkens WJ, Carrillo T, Tabar $\mathrm{AI}$, et al. Efficacy and safety of sublingual tablets of house dust mite allergen extracts in adults with allergic rhinitis. J Allergy Clin Immunol 2014;133:1608-14. e6.

6. Linkov G, Toskala E. Sublingual immunotherapy: what we can learn from the European experience. Curr Opin Otolaryngol Head Neck Surg 2014;22:208-10.

7. Calderon MA, Casale TB, Nelson HS, Demoly P. An evidence-based analysis of house dust mite allergen immunotherapy: a call for more rigorous clinical studies. J Allergy Clin Immunol 2013;132:132236.

8. Kim SH, Mun SJ, Han DH, Kim JW, Kim DY, Rhee CS. Three-Year Follow-up Results of Sublingual Immunotherapy in Patients With Allergic Rhinitis Sensitized to House Dust Mites. Allergy Asthma Immunol Res 2015;7:118-23.

9. Trebuchon F, Lhéritier-Barrand M, David M, Demoly P. Characteristics and management of sublingual allergen immunotherapy in children with allergic rhinitis and asthma induced by house dust mite allergens. Clin Transl Allergy 2014;4:15.

10. Wang DH, Chen L, Cheng L, Li KN, Yuan H, Lu JH, et al. Fast onset of action of sublingual immunotherapy in house dust mite-induced allergic rhinitis: a multicenter, randomized, double-blind, placebo-controlled trial. Laryngoscope 2013;123:1334-40.

11. Yonekura S, Okamoto Y, Sakurai D, Horiguchi S, Hanazawa T, Nakano A, et al. Sublingual immunotherapy with house dust extract for house dust-mite allergic rhinitis in children. Allergol Int 2010;59:381-8.

12. Marogna M, Spadolini I, Massolo A, Canonica GW, Passalacqua G. Randomized controlled open study of sublingual immunotherapy for respiratory allergy in real-life: clinical efficacy and more. Allergy 2004;59:1205-10.

13. Yukselen A, Kendirli SG, Yilmaz M, Altintas DU, Karakoc GB. Two year follow-up of clinical and inflammation parameters in children monosensitized to mites undergoing subcutaneous and sublingual immunotherapy. Asian Pac J Allergy Immunol 2013;31:233-41.

14. Tahamiler R, Saritzali G, Canakcioglu S. Long-term efficacy of sublingual immunotherapy in patients with perennial rhinitis. Laryngoscope 2007;117:965-9.

15. Marogna M, Bruno M, Massolo A, Falagiani P. Long-lasting effects of sublingual immunotherapy for house dust mites in allergic rhinitis with bronchial hyperreactivity: a long-term (13-year) retrospective study in real life. Int Arch Allergy Immunol 2007;142:70-8.

16. Han DH, Choi YS, Lee JE, Kim DY, Kim JW, Lee CH, et al. Clinical efficacy of sublingual immunotherapy in pediatric patients with allergic rhinitis sensitized to house dust mites: comparison to adult patients. Acta Otolaryngol 2012;132 Suppl 1:S88-93.

17. Marcucci F, Sensi L, Di Cara G, Salvatori S, Bernini M, Pecora S, et al. Three-year follow-up of clinical and inflammation parameters in children monosensitized to mites undergoing sub-lingual immunotherapy. Pediatr Allergy Immunol 2005;16:519-26.

18. Cosmi L, Santarlasci V, Angeli R, Liotta F, Maggi L, Frosali F, et al. Sublingual immunotherapy with Dermatophagoides monomeric allergoid down-regulates allergen-specific immunoglobulin $\mathrm{E}$ and increases both interferon-gamma- and interleukin-10-production. Clin Exp Allergy 2006;36:261-72. 